\title{
Bridging the Gap Among Professionals Who Address Youths With School Absenteeism: Overview and Suggestions for Consensus
}

\author{
Christopher A. Kearney \\ University of Nevada, Las Vegas
}

\begin{abstract}
Over decades of study, problematic school absenteeism in youths has been associated with diverse terms such as truancy, psychoneurotic truancy, school refusal, school phobia, and separation anxiety. Unfortunately, such disparity has led to lack of consensus regarding definition, assessment, and treatment for this population. This is especially problematic given that school absenteeism and dropout remain at crisis proportions. A brief historical overview is presented of the various terms used to define subtypes of absenteeism. Suggestions are then made for building consensus among psychologists, educators, and others who address these youths. These suggestions surround using a common definitional and assessment approach as well as designing treatment strategies that cover all youths with problematic absenteeism.
\end{abstract}

Problematic school absenteeism in youths has been researched and discussed extensively for over a century, receiving attention from psychologists of different theoretical orientations as well as educators, social workers, physicians, and others. A byproduct of this extensive attention, however, has been considerable disparity about fundamental concepts of definition, assessment, and treatment. Such disparity has been manifested by the presence of different sets of professionals who often evaluate a particular aspect of problematic school absenteeism at the expense of viewing the population as a whole. As a result, practitioners, researchers, and others are often "not on the same page" when addressing students or clients, examining research samples, or classifying absentees.

Such lack of consensus is especially problematic given that $5.5 \%-20.0 \%$ of youths are absent from school on a given day and that $11.1 \%$ of youths aged 16-24 years have dropped out of school (Bell, Rosen, \& Dynlacht, 1994; National Center for Education Statistics, 1998). In addition, school absenteeism may result in several severe short-term consequences, including declining grades, legal difficulties, social alienation, family conflict, and distress (Kearney, 2001). Long-term consequences of absenteeism include juvenile delinquency, school dropout, and occupational and social problems in adulthood (Buitelaar, van Andel, Duyx, \& van Strien, 1994; Hibbett \& Fogelman, 1990). Because of the severity of absenteeism, clinicians and researchers must work together and operate on a common footing to design a comprehensive response.

The purposes of this article are thus to (a) briefly review historical roots and definitions regarding hypothesized constructs

Christopher A. Kearney received his PhD in clinical psychology from the State University of New York at Albany. He is an associate professor of psychology at the University of Nevada, Las Vegas. His research interests include the conceptualization, assessment, and treatment of youths with school refusal behavior and anxiety-related disorders.

CORRESPONDENCE CONCERNING THIS ARTICLE should be addressed to Christopher A. Kearney, Department of Psychology, University of Nevada, 4505 Maryland Parkway, Las Vegas, Nevada 89154-5030. E-mail: ckearney@ccmail.nevada.edu of problematic school absenteeism and (b) provide suggestions for standardizing the conceptualization of this population for those who address this population. The points suggested here are not meant to be the final word in this area but, rather, a starting point for building a much needed consensus regarding definition, assessment, and treatment. The reader should note that literature from Western societies is emphasized given that data have primarily emanated from these countries. However, information from other (e.g., Asian) countries will have to be considered as it emerges.

\section{Overview: Compulsory Education and Truancy}

During the 19th century, the United States and European countries enacted laws to mandate school attendance and move youths from work to educational settings. As industrialization, urbanization, and immigration increased, compulsory education and child labor laws were thought necessary to preserve social order and provide a competent workforce. The compulsory education movement led to the conceptualization of school absenteeism as a serious social and behavioral problem that required study and resolution. Authors of the earliest scientific articles on problematic school absenteeism, mostly from education and psychology, often combined legal and psychological definitions and relied on the term truancy. Truancy was typically referred to as an unlawful and willful "absence from school without the knowledge and consent of the parents" (Williams, 1927, p. 277). The problem was linked to delinquency, poor parenting, deviant peer influence, problematic school environments, school maladjustment, lack of motivation, and lower intelligence (Dayton, 1928; Doll, 1921; Kirkpatrick \& Lodge, 1935; McElwee, 1931; Mercer, 1930).

\section{Psychoneurotic Truancy/School Refusal}

The idea that problematic school absenteeism was generally linked to delinquency was questioned in a series of 1932-1941 articles. Specifically, a subtype of neurotic delinquency (Lippman, 1936) was identified in some youths who appeared anxious and depressed while committing supposedly delinquent truancy. Broadwin (1932) and Partridge (1939), for example, identified subtypes of youths who refused school with heterogeneous neu- 
rotic, antagonistic, and negativistic conditions. Partridge labeled his subtype psycho-neurotic truancy, which helped splinter the study of problematic absenteeism into (a) traditionalists, who viewed the problem as illegal, delinquent behavior (truancy), and (b) contemporaries, who viewed the problem as a complex neurotic condition (psychoneurotic truancy). Following Hersov (1960) and others, the synonymous term school refusal became preferred over psychoneurotic truancy and is commonly used today.

\section{School Phobia/Separation Anxiety}

A further splintering of problematic school absenteeism was created by Johnson, Falstein, Szurek, and Svendsen (1941), who contended that some children with problematic absenteeism display school phobia, or a form of psychoneurotic disorder. Previous conceptualizations of psychoneurotic truancy/school refusal were broader in that they contained aspects of what is now called negative affectivity. Johnson et al.'s (1941) school phobia, however, was considered a more specific subtype. In particular, school phobia was thought to consist of acute anxiety, phobic, hypochondriacal, and obsessive-compulsive symptoms as well as motherchild overdependence. Johnson later claimed that school phobia was a misnomer and that the problem was actually due to parentchild separation anxiety (Estes, Haylett, \& Johnson, 1956; Johnson, 1957). Separation anxiety refers to intense distress following anticipated or actual separation from significant others. Johnson's latter interpretation became quite popular and may have served as the basis for contemporary diagnostic criteria for separation anxiety disorder (American Psychiatric Association, 2000). Despite Johnson's reconceptualization, however, school phobia has remained a popular moniker.

\section{Modification of School Phobia}

Initially, school phobia involved a specific, anxiety-based component of the broader concept of psychoneurotic truancy/school refusal. Confusion among school phobia and psychoneurotic truancy/school refusal began to occur in the late 1940s to mid-1950s, however, as several authors linked school phobia to broader comorbid conditions, like somatic complaints, depression, family conflict, and even aspects of traditional truancy (e.g., Agras, 1959; Campbell, 1955; Suttenfield, 1954; Talbot, 1957; Warren, 1948). The original distinction between specific school phobia and general psychoneurotic truancy/school refusal was further blurred in the 1950 s by a reconceptualization of school phobia as more general "dread" and by a proposed branch of school phobia that included a broader based characterological subtype (Coolidge, Hahn, \& Peck, 1957; Waldfogel, Coolidge, \& Hahn, 1957).

With the resurgence of behaviorism in the 1960 s, school phobia was again defined more specifically. For example, school phobia was viewed by some behaviorists as an operationally defined fearful avoidance of school (e.g., Garvey \& Hegrenes, 1966; Lazarus, Davison, \& Polefka, 1965), which contrasted with other notions that the phenomenon was linked more to anxiety or negative affectivity. Kennedy (1965) also developed Type I and Type II categories that were based on more easily defined overt problems (e.g., grades) and duration of absenteeism. Others, however, continued to define school phobia in more global ways, linking the phenomenon to "severe emotional upset" that included fear, anger, somatic complaints, and general "misery" (Berg, Nichols, \& Prit- chard, 1969, p. 123), all aspects of psychoneurotic truancy/school refusal.

The early study of problematic absenteeism thus involved an initial split between traditional, delinquent truancy and psychoneurotic truancy/school refusal. Within the latter, school phobia was described as a specific anxiety/fear-based subtype. Concepts of school phobia, however, eventually became intertwined with, and thus quite similar to, original features used to describe psychoneurotic truancy/school refusal. Therefore, many people used, and still do use, the terms truancy, school refusal, school phobia, and separation anxiety interchangeably (Phelps, Cox, \& Bajorek, 1992). This has led to considerable confusion about how each term should be used and indicates the need for a communal definitional system.

\section{Empirical Distinctions}

Greater efforts were later made to empirically define constructs of absenteeism. Loosely basing their dichotomy on Achenbach's (1991a) empirically based internalizing-externalizing continuum, for example, Young, Brasic, Kisnadwala, and Leven (1990) proposed that internalizing school refusal disorder is marked by anxiety, phobia, depression, other emotional distress, and somatic complaints; externalizing truant disorder is marked by noncompliance, defiance, impulsivity, and conduct disorder symptoms. However, this dichotomy has not yet been supported empirically; many youths with absenteeism clearly evince symptoms of both poles, and the dichotomy has not clarified terminology in this area (Kearney \& Silverman, 1996).

Researchers have also tried to define problematic absenteeism statistically but with limited success. Kolvin, Berney, and Bhate (1984), for example, examined various dichotomies of school phobia using discriminant function analysis but found only one to be adequate (i.e., depressed-nondepressed). Berg and colleagues (1985), using principal-component factor analysis of parent ratings, identified a "truancy" component of problematic absenteeism that accounted for $20 \%$ of the variance and relied heavily on lack of parental knowledge about the problem. A "school refusal" component accounted for $15 \%$ of the variance and included behaviors such as staying home and resisting efforts to resume attendance.

Atkinson, Quarrington, Cyr, and Atkinson (1989), using cluster analysis, discerned three groups among $72 \%$ of a sample of youths with problematic absenteeism: (a) separation anxiety and overprotective mothers, (b) perfectionism/fear of failure, and (c) extensive school refusal and psychopathic deviancy. Finally, Bools, Foster, Brown, and Berg (1990) used cluster analysis to describe youths with severe nonattendance. Most $(68 \%)$ were assigned to a nonclinical group, and the rest were identified with refusal $(21 \%)$ or truancy $(11 \%)$. Overall, the substantial degree of overlap among identified groups as well as unexplained variance in these studies has not helped delineate consensual terminology for youths with absenteeism.

\section{Diagnostic Distinctions}

Concurrent with the empirical approach were attempts to define absenteeism diagnostically. In the Diagnostic and Statistical Manual of Mental Disorders (4th ed., text rev.; DSM-IV-TR; American Psychiatric Association, 2000), problematic absenteeism is listed 
as a symptom of (a) conduct disorder (i.e., "often truant from school, beginning before age 13 years," p. 90); this may reflect early work associating delinquency with traditional truancy, and (b) separation anxiety disorder (i.e., "persistent reluctance or refusal to go to school or elsewhere because of fear of separation," p. 113); this may reflect later work associating separation anxiety with psychoneurotic truancy/school refusal. In addition, specific phobia may include a panic-like response to a school stimulus, where a child avoids out of fear or endures the stimulus with great dread. Related symptoms in youths include "crying, tantrums, freezing, or clinging” (p. 410). This diagnosis may reflect early work associating specific fear and anxiety with school phobia. Of course, problematic school absenteeism has been associated with many other diagnoses as well (Kearney \& Silverman, 1996), including panic disorder and agoraphobia, social and generalized anxiety disorder, and oppositional defiant disorder, among others.

Proposals to define or classify problematic school absenteeism by means of diagnoses include Bernstein and Garfinkel (1986, 1988), who grouped youths with school phobia into those with affective disorder only, those with anxiety disorder only, those with affective and anxiety disorders, and those with neither affective nor anxiety disorder. Last and colleagues (Last, Francis, Hersen, Kazdin, \& Strauss, 1987; Last \& Strauss, 1990; Last, Strauss, \& Francis, 1987) also found that youths with a "phobic disorder of school" tend to meet criteria for another anxiety and/or affective disorder or no disorder. Among these diagnostic studies, however, samples were restricted to those with anxiety-based school phobia/refusal, so little progress was made in establishing a common terminology for all youths with problematic absenteeism.

\section{Comment on the Overview}

As the study of absenteeism has evolved and grown, so has an increasingly fractured state of terminology. The results of this disparity are troubling. For example, research is often split across disciplines, with "anxiety-based school refusal" often studied by clinical child psychologists and "delinquent-based truancy" often studied by educators, social workers, and criminal justice experts (e.g., Bell, Rosen, \& Dynlacht, 1994; King et al., 1998). Research articles on one type of absenteeism rarely mention other types. In addition, researchers sometimes use terms that imply that the entire population is being evaluated. For example, researchers may say that "truant youths" or "youths with school phobia/refusal" were examined (e.g., Last, Hansen, \& Franco, 1998). Unfortunately, given the chaotic definitional nature of the field, and especially given the fact that labels are often used interchangeably, readers may be unsure about how to consider these terms. It is not often clear, for example, that "school refusal" may refer only to youths with anxiety-based problems. Instead, readers may mistakenly believe that the definition, dependent measures, and/or treatment outcome data from a particular study apply to all youths with problematic absenteeism. Little consensus has thus been built regarding definition, assessment, and treatment for the entire spectrum of absenteeism. Following is a list of suggestions meant as a starting point for building such consensus.

\section{Suggestion 1: Distinguish Nonproblematic From Problematic Absenteeism}

One suggestion for building consensus is to ask professionals to first make clear whether they are examining nonproblematic or problematic absenteeism. Such a distinction would serve two purposes. First, it would begin to clarify for readers exactly what form of absenteeism is being evaluated. Second, information about the distinction would help empirically identify what best separates nonproblematic from problematic absenteeism. Many school districts and professionals currently use their own criteria to make this distinction, but this inhibits research regarding epidemiology and appropriate definition.

As a starting point for standardizing this distinction, nonproblematic absenteeism could refer to any formal school absence agreed on by parents and school officials as legitimate in nature and not involving detriment to the child. This would cover shortterm or temporary absences, self-corrective school absenteeism, and long-term absences attributable to illness, natural disaster, or other unusual conditions that are appropriately compensated for in some way (e.g., home schooling, vocational training, credit by examination). An important part of this definition, however, is that parents and school officials must agree that the absence is legitimate. Nonproblematic absenteeism would thus exclude, for example, cases where a parent claims legitimate absence when actually this is not so (e.g., school withdrawal). Self-corrective absenteeism may reflect youths with fleeting episodes of anxiety at the beginning of the school year or those who test their parents by acting out to stay home from school. In most cases, this type of absenteeism is managed independently and appropriately by parents or the children themselves.

Problematic absenteeism could refer to school-aged youths who (a) have missed most (i.e., $>50 \%$ ) school time for at least 2 weeks and/or (b) experience difficulty attending school for at least 2 weeks such that significant interference occurs in the child's or family's daily life routine. The latter may refer to youths who consistently skip certain classes, show frequent morning misbehaviors to try to miss school, and/or have considerable anxiety about school. Thus, a spectrum of problems is covered by the term, and subtyping may then begin (see below). A 2-week criterion also helps to ensure that temporary attempts at absenteeism, which are common and often not yet problematic, are excluded.

Problematic absenteeism could then be divided into non-childmotivated and child-motivated conditions. Non-child-motivated conditions may refer to circumstances that are largely beyond a child's control, such as parent-motivated school withdrawal (i.e., where a parent deliberately keeps a child home from school) or primary societal or familial triggers, such as homelessness or a desire to escape abuse. Extended problematic absenteeism may or may not lead eventually to school dropout.

\section{Suggestion 2: Use a Common Terminology for Child-Motivated Problematic Absenteeism}

To build further consensus and remedy the disparity of terms used to describe youths with child-motivated problematic absenteeism (an unwieldy phrase), the umbrella term of school refusal behavior may be used (Kearney \& Silverman, 1996). School refusal behavior refers to a child-motivated refusal to attend school or difficulty remaining in classes for an entire day. This atheoretical definition of school refusal behavior was designed to envelop prior descriptions of this population, including truancy, psychoneurotic truancy, school refusal, school phobia, and separation anxiety. The definition does so by relying on a well-defined 
continuum of actual school attendance illustrated in Figure 1 (Kearney, 2001).

One end (right) of this continuum includes youths who are completely and continuously absent from school for an extended period of time. Near this pole are youths who miss certain periods of the school year, such as those who refuse school for some time following a holiday or track break. Other youths miss only part of the school day by skipping classes or entering school late (tardiness). The continuum also includes youths who attend school much of the time but repeatedly misbehave in the morning to miss school and/or experience severe distress during the school day that precipitates pleas for future nonattendance.

School refusal behavior thus includes youths who "successfully" miss school as well as those who try to miss school but who have not yet reached that goal. The continuum accurately reflects the heterogeneity of school refusal behavior and adequately covers the entire population. In related fashion, the continuum is useful to clinicians and educators who must address children with very fluid types of absenteeism. Common to all points on the continuum is a disruption of age-appropriate functioning by failing to cope with school-related stressors and/or a desire to eliminate regular school attendance from daily life. The continuum is designed to apply to each episode of a child's school refusal behavior. That is, a certain youth may demonstrate multiple components of school refusal behavior (e.g., skip classes one day, be completely absent another day, experience test anxiety another day).

Each point on this continuum may also be described as acute or chronic (Kearney, 2001; Kearney \& Silverman, 1996). Historically, an acute-chronic distinction has been variously defined but often linked to duration of absenteeism. A suggestion for building consensus for this distinction can thus be based on common historical precedents (e.g., Berg et al., 1969). Specifically, acute school refusal behavior may refer to youths whose problem has lasted 2-52 weeks, whereas chronic school refusal behavior may refer to youths whose problem has lasted longer than one year. The latter necessitates school refusal behavior over two academic years, which is a poor prognostic sign for this population (Kearney, 1995).

Figure 2 summarizes the concepts suggested for consensus (Kearney, 2001). Initially, an episode of school absenteeism may be defined broadly as nonproblematic or problematic. Assuming it is problematic, the episode may be defined broadly as parent/otherfactor motivated (e.g., school withdrawal) or child-motivated. Either could lead to permanent school dropout. Assuming childmotivated problematic absenteeism (i.e., school refusal behavior), then an acute-chronic distinction may be made. This definitional model does not endorse any specific etiological pathway that led to an initial episode of school refusal behavior. Instead, various pathways proposed in the literature (e.g., phobia, separation anxiety, oppositional behavior, negative parent/school influences) can be considered using this general definitional model (see Kearney, 2001, for pathway examples).

Figure 2 allows for youths who enter different stages of absenteeism (note bidirectional arrows). For example, initially nonproblematic absenteeism could decompensate into a problematic state as a parent acquiesces more to a child's requests to stay home. For example, occasional episodes of self-corrective school refusal behavior could recur for gradually longer periods of time. Conversely, successful treatment of school refusal behavior could revert it to a nonproblematic state. The unidirectional arrow pointing to school dropout, however, represents the permanence of this phenomenon.

Figure 2 should be viewed in conjunction with Figure 1; each episode of school refusal behavior may be charted along the Figure 1 continuum. In addition, Kearney and colleagues have outlined functional subtypes of school refusal behavior that cover all youths with this problem (i.e., avoidance of stimuli provoking negative affectivity, escape from aversive social/evaluative situations, pursuit of attention, pursuit of tangible reinforcement outside of school; e.g., Kearney \& Silverman, 1996). This figure is not meant, however, to exclude other subtypes of school refusal behavior that could be, and have been, proposed (e.g., phobia, separation anxiety, conduct disorder). The model presented here simply serves as a starting point. Indeed, subtyping on the basis of the symptoms of school refusal behavior, a common research practice, can fit well into the different absenteeism patterns described here. For example, a socially anxious child may attend school under great duress, skip one class where an evaluation is expected, or avoid school altogether. Similarly, a child with oppositional behavior could be chronically late to school or skip out early. The proposed model helps provide greater information about a particular case than simple categorical labels of "school phobia" or "truancy." In essence, dimensional or more fluid aspects of absenteeism are additionally considered.

\section{Suggestion 3: Use This Definitional Model to Assist Communication and Research in the Area}

The proposed definitional model of school refusal behavior may be used to build communication among professionals and advance

\begin{tabular}{|c|c|c|c|c|c|c|}
\hline $\begin{array}{l}\text { School } \\
\text { attendance } \\
\text { under } \\
\text { duress } \\
\text { and pleas } \\
\text { for } \\
\text { nonattendan }\end{array}$ & $\begin{array}{l}\text { Repeated } \\
\text { misbehaviors } \\
\text { in the } \\
\text { morning to } \\
\text { avoid school }\end{array}$ & $\begin{array}{l}\text { Repeated } \\
\text { tardiness } \\
\text { in the } \\
\text { morning } \\
\text { followed by } \\
\text { attendance }\end{array}$ & $\begin{array}{l}\text { Periodic } \\
\text { absences or } \\
\text { skipping of } \\
\text { classes }\end{array}$ & $\begin{array}{l}\text { Repeated } \\
\text { absences } \\
\text { or skipping } \\
\text { of classes } \\
\text { mixed with } \\
\text { attendance }\end{array}$ & $\begin{array}{l}\text { Complete } \\
\text { absence } \\
\text { from school } \\
\text { during a } \\
\text { certain } \\
\text { period of } \\
\text { the school } \\
\text { year }\end{array}$ & $\begin{array}{l}\text { Complete } \\
\text { absence } \\
\text { from } \\
\text { school for } \\
\text { an extended } \\
\text { period of } \\
\text { time }\end{array}$ \\
\hline
\end{tabular}

Figure 1. Continuum of school refusal behavior on the basis of attendance. From School Refusal Behavior in Youth: A Functional Approach to Assessment and Treatment (p. 7), by C. A. Kearney, 2001, Washington, DC: American Psychological Association. Copyright 2001 by the American Psychological Association. 
School Absenteeism

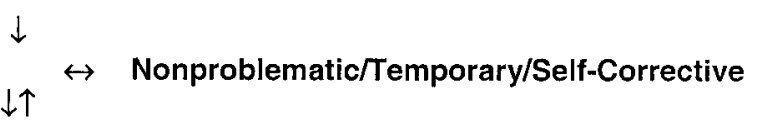

Problematic

$\downarrow \uparrow$

$\downarrow \uparrow$

$\leftrightarrow \quad \begin{gathered}\text { Parent-Motivated School } \\ \text { Withdrawal and/or Primary } \\ \text { Societal/Familial Triggers }\end{gathered} \rightarrow \begin{aligned} & \text { School } \\ & \text { Dropout }\end{aligned}$

Child-Motivated School Refusal Behavior

$\downarrow \uparrow$

\author{
Acute (2-52 weeks) or Chronic (53+ weeks) \\ (Note Continuum Of Attendance \\ and Functions Of School \\ Refusal Behavior)
}

$\downarrow$

School Dropout

Figure 2. Proposed chart for youths with school absenteeism. From School Refusal Behavior in Youth: A Functional Approach to Assessment and Treatment (p. 18), by C. A. Kearney, 2001, Washington, DC: American Psychological Association. Copyright 2001 by the American Psychological Association.

research regarding youths with absenteeism. Because the model covers all youths who refuse school, researchers, educators, and clinicians who address this population can have a common starting point for discussion (e.g., about a particular case). The substantial overlap and vagueness often seen with respect to previous terms (e.g., school phobia, refusal) is, at least initially, avoided.

The proposed model can also assist the development of research in several ways. First, the model provides balance by including youths with various symptom or functional patterns. Specifically, the model equally considers or weighs youths who refuse school for nonanxiety reasons. Recent treatment outcome (e.g., Bernstein et al., 2000; King et al., 1998; Last et al., 1998) and family (e.g., Bernstein, Warren, Massie, \& Thuras, 1999) studies tend to concentrate on youths who are anxious about school at the expense of the more substantial number of youths who miss school without apparent anxiety. Adoption of the model may stimulate more research about youths who show other (i.e., nonanxious) symptom patterns.

Second, the components of the definitional model may be used to advance research regarding the prevalence of absenteeism. Many school districts and states, for example, collect their own information about absences, partial absences, and tardiness. In addition, clinical researchers often focus on the prevalence of school-based anxiety using their own criteria (e.g., Granell de Aldaz, Vivas, Gelfand, \& Feldman, 1984; see Kearney, 2001, for review). In addition to the need to obtain comparable prevalence rates using standard definitions of absenteeism, work is needed to clarify and delineate prevalence rates of different kinds of absenteeism for different types of children. It may be, for example, that younger children show more tardiness and distress about school, whereas adolescents skip more classes or miss entire school days.

Third, the proposed definitional model is quite amenable to reliability and validity analysis. Instead of relying on amorphous terms such as "severe emotional upset" or "persistent reluctance to go to school," for example, the present model relies on more specific parameters (e.g., number of days or classes missed/days late, ratings of anxiety intensity) that can be readily tested for consistency. In addition, the model is amenable to longitudinal or retrospective analysis to assess its validity. For example, youths with problematic absenteeism can be followed over time to see whether any behaviors fall outside the model's parameters. In addition, retrospective analyses of youths who have dropped out of school may be done to see whether the model's pathways apply to them or require alteration.

\section{Suggestion 4: Use This Definitional Model to Select Assessment and Treatment Targets}

The proposed definitional model may enhance the development of common assessment and treatment targets for youths with absenteeism. From a developmental psychopathology viewpoint, for example, the model could be used to help examine patterns of absenteeism as well as factors that predict change (or no change) in pathways leading to school refusal behavior, withdrawal, and dropout. High-priority factors would include individual as well as school, community, and other variables derived from the literature (e.g., frequent teacher absences, school violence and class disruptions, ethnic/racial dissonance). Much work has been done with 
respect to school dropout, for example (Corville-Smith, Ryan, Adams, \& Dalicandro, 1998; Jenkins, 1995; Kearney \& Hugelshofer, 2000; Kortering \& Blackorby, 1992; McWhirter, McWhirter, McWhirter, \& McWhirter, 1998), so this work could serve as one starting point.

Knowledge about these pathways would clearly assist in developing intervention and prevention programs. For example, many children initially skip classes and assess their parents' reactions. Should parental acquiescence result, then a child may be more apt to miss entire days of school. Knowledge of such a pathway is important for treatment. In this case, for example, parent training in contingency management and increased supervision of the child might be appropriate to stem further absences. School districts could also examine patterns of well-defined absenteeism to identify youths at risk for dropout and to design subsequent preventive programs.

For practitioners who address youths with school refusal behavior, developmental pathways can be identified and classified as early as the screening and assessment process. In fact, the definitional model presented here reveals several key target areas of assessment for practitioners. First, number and type of absences is clearly important and may be derived from a combination of child, parent, teacher, and school attendance officer reports (child reports are especially important for distress during classes or surreptitiously missed classes). Second, practitioners should focus on whether a child's absenteeism is primarily related to parentmotivated school withdrawal or other factors, such as illness, pregnancy, homelessness, maltreatment, or legitimate threats at school. This may be done by interviewing relevant family members, educators (e.g., guidance counselors), and medical personnel as well as reviewing recent academic, housing, and medical records. Parental investment in the therapy process should be closely monitored by practitioners as well.

A third key assessment target is how long a child has been out of school or has tried to miss school. Again, reports from all relevant parties are important. More extensive school refusal behavior, as noted earlier, is closely related to poor prognosis and school dropout. Therefore, intense, frequent, and immediate intervention that involves several parties is often necessary. Finally, the history of a child's school refusal behavior can also illuminate developmental patterns (e.g., anxiety, depression) that can help a clinician identify important early directions of treatment. In particular, the forms and functions of a child's school refusal behavior should be thoroughly assessed. Practitioners should pay special attention to a child's patterns of anxiety, depression, somatic complaints, noncompliance, aggression, tantrums, and flight behaviors, especially in the morning. The primary functions of school refusal behavior (e.g., to avoid/escape aversive schoolrelated stimuli, to pursue attention or tangible reinforcement) should be examined as well. Common methods of assessing the forms and functions of school refusal behavior include interviews, questionnaires (see next section), self-monitoring ratings and observations from others, and ongoing consultations with school personnel (see Kearney \& Albano, 2000).

\section{Suggestion 5: Develop a Common, General Assessment Approach for This Population}

Along with varying definitions, a key drawback among characteristic and treatment outcome studies of absentee youths is that various assessment or dependent measures are used. Much of this is due to the fact that virtually any assessment device is potentially relevant to this heterogeneous population. Unfortunately, however, a lack of consensus makes it difficult to compare studies or group them to derive meta-analytic-like conclusions. To address this, clinicians, researchers, and others may consider using a pool of common, standardized instruments and other procedures to assess constructs associated most with this population.

What instruments and procedures may match up best with different components of school refusal behavior as proposed in the definitional model (Figure 1)? For youths who attend school under duress and who issue constant pleas for nonattendance, subjective areas of anxiety, depression, and other internalizing states are important to assess. The child self-report section of Table 1 contains some commonly used questionnaires that may be useful in this regard. A child's daily ratings of negative affectivity, child and parent reports of anxiety-based or excessive reassurance-seeking behavior (e.g., Anxiety Disorders Interview Schedule for Children [ADIS-C]), and school official reports of avoidance would also be helpful. For youths who show repeated misbehaviors to miss school or who are chronically tardy to school, observations of the child during the morning routine and parent reports of disruptive behaviors are imperative. Table 1 contains examples of commonly used parent and teacher measures that cover externalizing behavior problems. Children of this group often claim physical problems as well, so consultation with a medical professional is recommended to identify any true organic problems (vs. attention-seeking misbehavior).

For youths who skip classes, almost always surreptitiously, increased supervision of their daily attendance is crucial. Therefore, a practitioner must work closely with teachers (often multiple ones) and school attendance officers so that any missed class can be reported immediately to the practitioner and/or the parents. In addition, parents should be encouraged to work closely with school officials so an immediate response to school refusal behavior can be implemented. Finally, for youths who miss considerable periods of the school year, practitioners should focus on family variables that help maintain this condition, perhaps by means of an interview, the family measures in Table 1, or other relevant procedures. In addition, school officials should be frequently contacted regarding scheduling, make-up work, policies for reintegration, and feedback about treatment effectiveness. For all youths with school refusal behavior, teacher ratings of child behavior are suggested, and common examples are listed in Table 1.

The suggestion of using a common pool of standardized instruments and procedures is not meant to restrict the development or use of various measures for this population. Indeed, measures specific to youths with absenteeism are far too few. Instead, professionals are encouraged to pursue some similarity of protocol in dependent measures so that research samples can be better compared. A perusal and matching of recent treatment outcome and characteristic studies from different disciplines might be helpful in this regard. Such a protocol could also include recommendations for synthesizing assessment information to identify the best treatment for a particular case.

\section{Suggestion 6: Develop Strategies to Treat All Youths With Problematic Absenteeism}

A definitional model is most useful if it covers all possible subtypes of a phenomenon like a youth behavior problem. In this 
Table 1

Commonly Used Standardized Measures to Assess Youth With School Refusal Behavior

\begin{tabular}{ll}
\hline \multicolumn{1}{c}{ Standardized measure } & \multicolumn{1}{c}{ Source } \\
\hline \multicolumn{1}{c}{ Parent and child interview } \\
Anxiety Disorders Interview Schedule for Children & \multicolumn{1}{c}{$\begin{array}{l}\text { See school refusal behavior section; } \\
\text { Silverman \& Albano, 1996 }\end{array}$} \\
\hline \multicolumn{1}{c}{ Child self-report } \\
\end{tabular}

Parent and teacher report

Child Behavior Checklist

Conners Rating Scales-Revised (parent/teacher versions)

Family Assessment Measure

Family Environment Scale

School Refusal Assessment Scale (parent version)

Teacher Report Form
Achenbach, 1991a

Conners, 1997

Skinner, Steinhauer, \& Santa-Barbara, 1983

Moos \& Moos, 1986

Kearney \& Silverman, 1993

Achenbach, 1991b way, treatments can be developed to address any form of the problem. The current state of treatment study for youths with problematic absenteeism is of high quality but limited in scope. Available to readers are excellent outcome studies that have focused on systemic methods of curbing full-day absences (see Duckworth, 1988; Miller, 1986; Stine, 1990; Tuck \& Shimburi, 1988) as well as those that have focused on anxiety-based problems (e.g., Bernstein et al., 2000; King et al., 1998; Last et al., 1998). These treatment studies represent a substantial advance in our knowledge of how to intervene with youths with problematic absenteeism. Such work must continue to be refined, but at last clinicians and educators have more clear ideas about designing their own treatment plans.

What treatment procedures may match up best with different components of school refusal behavior as proposed in the definitional model (Figure 1)? For youths who attend school under duress and who issue constant pleas for nonattendance, a common strategy is a child-based cognitive-behavioral approach that focuses on mastery of anxiety and worry as well as gradual reintegration into a regular classroom setting (see Table 2). For youths who show repeated misbehaviors to miss school or who are chronically tardy to school, a common strategy is a parent-based contingency management approach (see Table 2). Such an approach focuses on increasing order during the morning routine, establishing incentives for compliance and school attendance, and forced attendance with school official cooperation.

For youths who skip classes and/or miss considerable periods of time in school, a common strategy is a comprehensive, familybased approach that focuses on reducing conflict and obstacles to school attendance as well as increasing incentives for going to school (see Table 2). Such an approach concentrates on teaching negotiation skills to family members (e.g., through contracts and appropriate communication), increasing supervision of the child, helping the child refuse offers to miss school, and eliminating competing lures outside of school.

A drawback of some contemporary treatment outcome studies is that they are generally not linked to an overarching model of absenteeism. Instead, there is more focus on very specific subtypes

Table 2

Commonly Used Techniques to Treat Youths With School Refusal Behavior

Child-focused treatment

Psychoeducation

Cognitive restructuring

Somatic control exercises (e.g., relaxation/rebreathing training)

Exposure-based procedures (i.e., imaginal and in vivo reintegration into school)

Parent-focused treatment

Contingency management (rewards and punishments for attendance and nonattendance)

Establishing morning, daily, and evening routines

Limiting excessive reassurance-seeking behavior (e.g., asking same questions constantly)

Forced school attendance under certain circumstances

Family-focused treatment

Supportive psychotherapy

Contingency contracting

Escorting youth to school and classes

Communication skills training

Peer refusal skills training (to refuse offers to miss school) 
(e.g., children with only full-day absences or anxiety). The next step in designing interventions for this population will be to consider all youths with problematic absenteeism. Strategies for doing so will certainly require a multidisciplinary approach that will, it is hoped, bring researchers toward consensus about conceptualizing this population. Some have offered suggestions for doing so. In Kearney and colleagues' functional approach, for example, different prescriptive treatments are based on the reasons why a child refuses school and are meant to cover any child with school refusal behavior (see Kearney \& Albano, 2000; Kearney \& Silverman, 1990, 1999). This is only one example, however, and researchers are encouraged to find increasingly effective strategies for treating all youths with problematic absenteeism.

\section{Suggestion 7: Develop Methods to Gather Professionals Who Address This Population}

Clinicians, educators, and researchers who address youths with absenteeism are spread throughout psychology, education, social work, medicine, sociology, criminal justice, and other disciplines. To date, however, there has been little attempt to coalesce these different points of view regarding problematic absenteeism. Such splintering has led to general stagnation about a problem that nears crisis proportions.

A final suggestion for building consensus among these disciplines is to develop interest groups to gather professionals who address this population. Methods of doing so may include meetings at selected conferences, development of Web sites, increased linkages to national associations (e.g., National Dropout Prevention Center), and collaboration on grant proposals for multiple site studies. Until there is greater dialogue among those who most often deal with absenteeism, the field will continue to risk being muddled.

\section{References}

Achenbach, T. M. (1991a). Manual for the Child Behavior Checklist/4-18 and 1991 profile. Burlington: University of Vermont, Department of Psychiatry.

Achenbach, T. M. (1991b). Manual for the Teacher's Report Form and 1991 profile. Burlington: University of Vermont, Department of Psychiatry.

Achenbach, T. M. (1991c). Manual for the Youth Self-Report and 1991 profile. Burlington: University of Vermont, Department of Psychiatry.

Agras, S. (1959). The relationship of school phobia to childhood depression. American Journal of Psychiatry, 116, 533-536.

American Psychiatric Association. (2000). Diagnostic and statistical manual of mental disorders (4th ed., text revision). Washington, DC: Author.

Atkinson, L., Quarrington, B., Cyr, J. J., \& Atkinson, F. V. (1989). Differential classification in school refusal. British Journal of Psychiatry, 155, 191-195.

Bell, A. J., Rosen, L. A., \& Dynlacht, D. (1994). Truancy intervention. Journal of Research and Development in Education, 27, 203-211.

Berg, I., Casswell, G., Goodwin, A., Hullin, R., McGuire, R., \& Tagg, G. (1985). Classification of severe school attendance problems. Psychological Medicine, 15, 157-165.

Berg, I., Nichols, K., \& Pritchard, C. (1969). School phobia: Its classification and relationship to dependency. Journal of Child Psychology and Psychiatry, 10, 123-141.

Bernstein, G. A., Borchardt, C. M., Perwein, A. R., Crosby, R. D., Kushner, M. G., Thuras, P. D., \& Last, C. G. (2000). Imipramine plus cognitive-behavioral therapy in the treatment of school refusal. Journal of the American Academy of Child and Adolescent Psychiatry, 39, 276-283.

Bernstein, G. A., \& Garfinkel, B. D. (1986). School phobia: The overlap of affective and anxiety disorders. Journal of the American Academy of Child and Adolescent Psychiatry, 25, 235-241.

Bernstein, G. A., \& Garfinkel, B. D. (1988). Pedigrees, functioning, and psychopathology in families of school phobic children. American Journal of Psychiatry, 145, 70-74.

Bernstein, G. A., Warren, S. L., Massie, E. D., \& Thuras, P. D. (1999). Family dimensions in anxious-depressed school refusers. Journal of Anxiety Disorders, 13, 513-528.

Bools, C., Foster, J., Brown, I., \& Berg, I. (1990). The identification of psychiatric disorders in children who fail to attend school: A cluster analysis of a non-clinical population. Psychological Medicine, 20, 171181.

Broadwin, I. T. (1932). A contribution to the study of truancy. American Journal of Orthopsychiatry, 2, 253-259.

Buitelaar, J. K., van Andel, H., Duyx, J. H. M., \& van Strien, D. C. (1994). Depressive and anxiety disorders in adolescence: A follow-up study of adolescents with school refusal. Acta Paedopsychiatrica, 56, 249-253.

Campbell, J. D. (1955). Manic-depressive disease in children. Journal of the American Medical Association, 158, 154-157.

Conners, C. K. (1997). Conners Rating Scales-Revised. North Tonawanda, NY: Multi-Health Systems.

Coolidge, J. C., Hahn, P. B., \& Peck, A. L. (1957). School phobia: Neurotic crisis or way of life? American Journal of Orthopsychiatry, 27, 296306.

Corville-Smith, J., Ryan, B. A., Adams, G. R., \& Dalicandro, T. (1998). Distinguishing absentee students from regular attenders: The combined influence of personal, family, and school factors. Journal of Youth and Adolescence, 27, 629-640.

Dayton, N. (1928). Mental deficiency and other factors that influence school attendance. Mental Hygiene, 12, 794-800.

Doll, E. A. (1921). Mental types, truancy, and delinquency. School and Society, 14, 482-485.

Duckworth, K. (1988). Coping with student absenteeism. The Practitioner, 14, 1-14.

Estes, H. R., Haylett, C. H., \& Johnson, A. M. (1956). Separation anxiety. American Journal of Orthopsychiatry, 26, 682-695.

Garvey, W. P., \& Hegrenes, J. R. (1966). Desensitization techniques in the treatment of school phobia. American Journal of Orthopsychiatry, 36, $147-152$.

Granell de Aldaz, E., Vivas, E., Gelfand, D. M., \& Feldman, L. (1984). Estimating the prevalence of school refusal and school-related fears. Journal of Nervous and Mental Disease, 172, 722-729.

Hersov, L. A. (1960). Persistent non-attendance at school. Journal of Child Psychology and Psychiatry, 1, 130-136.

Hibbett, A., \& Fogelman, K. (1990). Future lives of truants: Family formation and health-related behaviour. British Journal of Educational Psychology, 60, 171-179.

Jenkins, P. H. (1995). School delinquency and school commitment. Sociology of Education, 68, 221-239.

Johnson, A. M. (1957). School phobia. American Journal of Orthopsychiatry, 27, 307-309.

Johnson, A. M., Falstein, E. I., Szurek, S. A., \& Svendsen, M. (1941). School phobia. American Journal of Orthopsychiatry, 11, 702-711.

Kearney, C. A. (1995). School refusal behavior. In A. R. Eisen, C. A. Kearney, \& C. E. Schaefer (Eds.), Clinical handbook of anxiety disorders in children and adolescents (pp. 19-52). Northvale, NJ: Jason Aronson.

Kearney, C. A. (2001). School refusal behavior in youth: A functional approach to assessment and treatment. Washington, DC: American Psychological Association.

Kearney, C. A., \& Albano, A. M. (2000). When children refuse school: A 
cognitive-behavioral therapy approach: Therapist guide. San Antonio, TX: Psychological Corporation.

Kearney, C. A., Drabman, R. S., \& Beasley, J. F. (1993). The trials of childhood: The development, reliability, and validity of the Daily Life Stressors Scale. Journal of Child and Family Studies, 2, 371-388.

Kearney, C. A., \& Hugelshofer, D. S. (2000). Systemic and clinical strategies for preventing school refusal behavior in youth. Journal of Cognitive Psychotherapy, 14, 1-15.

Kearney, C. A., \& Silverman, W. K. (1990). A preliminary analysis of a functional model of assessment and treatment for school refusal behavior. Behavior Modification, 14, 340-366.

Kearney, C. A., \& Silverman, W. K. (1993). Measuring the function of school refusal behavior: The School Refusal Assessment Scale. Journal of Clinical Child Psychology, 22, 85-96.

Kearney, C. A., \& Silverman, W. K. (1996). The evolution and reconciliation of taxonomic strategies for school refusal behavior. Clinical Psychology: Science and Practice, 3, 339-354.

Kearney, C. A., \& Silverman, W. K. (1999). Functionally-based prescriptive and nonprescriptive treatment for youth with school refusal behavior. Behavior Therapy, 30, 673-695.

Kennedy, W. A. (1965). School phobia: Rapid treatment of 50 cases. Journal of Abnormal Psychology, 70, 285-289.

King, N. J., Tonge, B. J., Heyne, D., Pritchard, M., Rollings, S., Young, D., et al. (1998). Cognitive-behavioral treatment of school-refusing children: A controlled evaluation. Journal of the American Academy of Child and Adolescent Psychiatry, 37, 395-403.

Kirkpatrick, M. E., \& Lodge, T. (1935). Some factors in truancy. Mental Hygiene, 14, 610-618.

Kolvin, I., Berney, T. P., \& Bhate, S. R. (1984). Classification and diagnosis of depression in school phobia. British Journal of Psychiatry, 145, 347-357.

Kortering, L. J., \& Blackorby, J. (1992). High school dropout and students identified with behavioral disorders. Behavioral Disorders, 18, 24-32.

Kovacs, M. (1992). Children's Depression Inventory manual. North Tonawanda, NY: Multi-Health Systems.

La Greca, A. M., \& Stone, W. L. (1993). Social Anxiety Scale for Children-Revised: Factor structure and concurrent validity. Journal of Clinical Child Psychology, 22, 17-27.

Last, C. G., Francis, G., Hersen, M., Kazdin, A. E., \& Strauss, C. C. (1987). Separation anxiety and school phobia: A comparison using DSM-III criteria. American Journal of Psychiatry, 144, 653-657.

Last, C. G., Hansen, C., \& Franco, N. (1998). Cognitive-behavioral treatment of school phobia. Journal of the American Academy of Child and Adolescent Psychiatry, 37, 404-411.

Last, C. G., \& Strauss, C. C. (1990). School refusal in anxiety-disordered children and adolescents. Journal of the American Academy of Child and Adolescent Psychiatry, 29, 31-35.

Last, C. G., Strauss, C. C., \& Francis, G. (1987). Comorbidity among childhood anxiety disorders. Journal of Nervous and Mental Disease, 175, 726-730.

Lazarus, A. A., Davison, G. C., \& Polefka, D. A. (1965). Classical and operant factors in the treatment of a school phobia. Journal of Abnormal Psychology, 70, 225-229.

Lippman, H. S. (1936). The neurotic delinquent. American Journal of Orthopsychiatry, 7, 114-121.

March, J. (1997). Multidimensional Anxiety Scale for Children. North Tonawanda, NY: Multi-Health Systems.

McElwee, E. W. (1931). A study of truants and retardation. Journal of Juvenile Research, 15, 209-214.
McWhirter, J. J., McWhirter, B. T., McWhirter, A. M., \& McWhirter, E. H. (1998). At-risk youth: A comprehensive response for counselors, teachers, psychologists, and human service professionals. Pacific Grove, CA: Brooks/Cole.

Mercer, M. L. (1930). School maladjustment as a factor in juvenile delinquency. Journal of Juvenile Research, 14, 41-42.

Miller, D. (1986). Effects of a program of therapeutic discipline on the attitude, attendance and insight of truant adolescents. Journal of Experimental Education, 55, 49-53.

Moos, R. H., \& Moos, B. S. (1986). Family Environment Scale manual (2nd. ed.). Palo Alto, CA: Consulting Psychologists Press.

National Center for Education Statistics. (1998). The condition of education 1998. Washington, DC: U.S. Department of Education.

Ollendick, T. H. (1983). Reliability and validity of the Revised Fear Survey Schedule for Children (FSSC-R). Behaviour Research and Therapy, 21, 685-692.

Partridge, J. M. (1939). Truancy. Journal of Mental Science, 85, 45-81.

Phelps, L., Cox, D., \& Bajorek, E. (1992). School phobia and separation anxiety: Diagnostic and treatment comparisons. Psychology in the Schools, 29, 384-394.

Reynolds, C. R., \& Paget, K. D. (1983). National normative and reliability data for the revised Children's Manifest Anxiety Scale. School Psychology Review, 12, 324-336.

Ronan, K. R., Kendall, P. C., \& Rowe, M. (1994). Negative affectivity in children: Development and validation of a self-statement questionnaire. Cognitive Therapy and Research, 18, 509-528.

Silverman, W. K., \& Albano, A. M. (1996). The Anxiety Disorders Interview Schedule for Children for DSM-IV, child and parent versions. San Antonio, TX: Psychological Corporation.

Skinner, H. A., Steinhauer, P. D., \& Santa-Barbara, J. (1983). The Family Assessment Measure. Canadian Journal of Community Mental Health 2, 91-105.

Spielberger, C. D. (1973). Manual for the State-Trait Anxiety Inventory for Children. Palo Alto, CA: Consulting Psychologists Press.

Stine, M. D. (1990). Do your students a favor and get tough on truants. Executive Educator, 12, 12-13.

Suttenfield, V. (1954). School phobia: A study of five cases. American Journal of Orthopsychiatry, 24, 368-380.

Talbot, M. (1957). Panic in school phobia. American Journal of Orthopsychiatry, 27, 286-295.

Tuck, K. D., \& Shimburi, F. N. (1988). An evaluation of the truancy prevention plan. Washington, DC: District of Columbia Public Schools.

Waldfogel, S., Coolidge, J. C., \& Hahn, P. B. (1957). The development, meaning, and management of school phobia. American Journal of Orthopsychiatry, 27, 754-780.

Warren, W. (1948). Acute neurotic breakdown in children with refusal to go to school. Archives of Disease in Childhood, 23, 266-272.

Williams, H. D. (1927). Truancy and delinquency. Journal of Applied Psychology, 11, 276-288.

Young, J. G., Brasic, J. R., Kisnadwala, H., \& Leven, L. (1990). Strategies for research on school refusal and related nonattendance at school. In C. Chiland \& J. G. Young (Eds.), Why children reject school: Views from seven countries (pp. 199-223). New Haven, CT: Yale University Press.

Received September 17, 2001

Revision received June 24, 2002

Accepted September 25, 2002 